\title{
UNUSUAL VARIATIONS IN PATH OF ACCESSORY SUBMANDIBULAR SALIVARY GLAND DUCT IN COMPARISON WITH MAIN SUBMANDIBULAR SALIVARY GLAND DUCT
}

\author{
Anita* $^{*}$ Saryu Sain ${ }^{\star *}$, Amrita Gupta*** \\ *Department of Anatomy, Jaipur National University Institute for Medical Sciences and Research Centre, Jaipur, \\ Rajasthan, India \\ ${ }^{*}$ Department of Anatomy, Pandit Deendayal Upadhyay Medical College, Churu, Rajasthan, India \\ ${ }^{* * *}$ Department of Anatomy, Varunarjun Medical College and Research Hospital, Shahjahanpur, UP, India
}

\begin{abstract}
Introduction: The submandibular gland is located bilaterally in the submandibular triangle. The main submandibular duct or Wharton's duct, runs with lingual nerve to open in the sublingual papilla at the side of frenulum of the tongue. The aim of this study was to demonstrate the unusual variations of accessory submandibular duct in comparison with main submandibular salivary gland duct.
\end{abstract}

Material \& Methods: Nineteen cadavers were dissected to study the submandibular salivary duct.

Results: $15.7 \%$ incidence of variations were observed. We found that one submandibular region was having unusual path of accessory duct, it emerged from superficial part of the gland and crossed the superficial surface of mylohyoid muscle and bifurcated into two branches. These bifurcated branches of duct pierced the mylohyoid muscle to pass between mylohyoid and hyoglossus muscle. One branch of bifurcated accessory duct opened through papilla in the floor of the mouth behind the lower incisor tooth and second branch of the bifurcated duct anastomosed with the main duct (Wharton's duct) to open in sublingual papilla. Wharton's duct of this side followed its normal path to open in the sublingual papilla. Two specimens of submandibular region was observed with duplication of submandibular duct in each submandibular gland. One was main duct and second was accessory duct. Both ducts emerged separately from the deep part of submandibular gland and ended independently into sublingual papilla.

Conclusion: Reporting of these variations are important for diagnostic imaging, anatomical teaching and to help surgeons while operating in this region.

Keywords: Submandibular gland, accessory submandibular duct, Wharton's duct, variation, sialography

\section{INTRODUCTION}

Submandibular salivary gland is irregular in shape and about the size of a walnut. It consists of a larger superficial and smaller deep part, continuous with each other around the posterior border of mylohyoid. It is a seromucous (but predominantly serous) gland $[1,2]$. The gland is drained by a single submandibular duct or Wharton's duct [2-4] is about $5 \mathrm{~cm}$ long. It begins from numerous tributaries in the superficial part of the gland a little behind the posterior border of the mylohyoid and then it traverses the deep part of the gland. It runs forwards between mylohyoid and hyloglossus to open in the floor of the mouth (linguogingival) on the summit of the sublingual papilla on each side of the frenulum of the tongue. The main function is to conduct the saliva to the oral cavity [1]. The duct lies between the lingual and hypoglossal nerve on hyoglossus muscle. The lingual nerve lies above the duct then crosses its lateral side and finally ascends medially winding round the lower border of

Address for Correspondence:

Dr Saryu Sain, Assistant Professor, Department of Anatomy, Pandit Deendayal Upadhyay Medical College, Churu, Rajasthan, India. Mob: 8949897469, 9430065823 Email: dr.anita.1709@gmail.com 
the duct. $[1,2]$.

The submandibular gland develops bilaterally during the $6^{\text {th }}$ week of fetal life. Glands form solid diverticula in linguogingival sulcus that undergo branching morphogenesis, the whole tree-like structure later acquiring a lumen. The blind ends of the branches form acini. The edges of the linguogingival sulcus come together to form the elongating submandibular duct [5].

Sialography is a diagnostic procedure of choice for the detection of structural variations of submandibular gland and duct including trauma, inflammatory disorders and calculi $[6,7]$. Most of the accessory submandibular duct are detected incidentally during sialography [8-10].

The practice of dissection of cadaver is very important because it allows one to verify the possible existence of structural differences in the human body.

The purpose of the study was to describe the anatomical variation in unusual path of accessory submandibular duct.

\section{MATERIALS AND METHODS}

A total of 19 adult embalmed cadavers were dissected and studied during routine dissection classes for $1^{\text {st }}$ year MBBS students in 2016-2018, in Anatomy department of Jaipur National University Institute for Medical Sciences and Research Centre, Jaipur, Rajasthan, India; Pandit Deendayal Upadhyay Medical College, Churu, Rajasthan, India and Varunarjun Medical College and Research Hospital, Shahjahanpur, Uttar Pradesh, India to determine the morphological features and anatomical variations in unusual path of accessory submandibular duct. The cadavers had no trace of scar, adhesions or signs of trauma or operation. The dissections were done bilaterally. Total 38 submandibular regions were dissected. Marginal mandibular incision were made from mastoid process to the chin and midline skin incision in neck from chin to the sternum was given to reflect the skin inferolaterally [11]. The submandibular gland, main submandibular duct or Wharton's duct and accessory submandibular duct were explored and examined for its emergence, course, unusual path and termination. The details of the variations were recorded and photographed.

\section{OBSERVATIONS AND RESULTS}

The present study was done on 19 cadavers, anatomical variation of accessory submandibular duct was found during routine dissection in 3 male cadavers i.e. total incidence was $15.7 \%$. Two submandibular ducts (duplication of duct) were found in two cases (10.5\%) and accessory submandibular duct with unusual path was found in one case (5.2\%). Variations were in the disposition, location and unusual path of the multiple accessory submandibular ducts.

In one cadaver, submandibular gland of left side had two submandibular ducts, the disposition and location with unusual path of the accessory submandibular gland duct was that the accessory duct of the left submandibular gland had an external location. It emerged from the superficial part of the gland and crossed horizontally the superficial surface of mylohyoid muscle for about $1 \mathrm{~cm}$. Then it bifurcated into two branches. These two branches of bifurcated ducts pierced the mylohyoid muscle and passed deep to mylohyoid muscle (Fig. 1A).

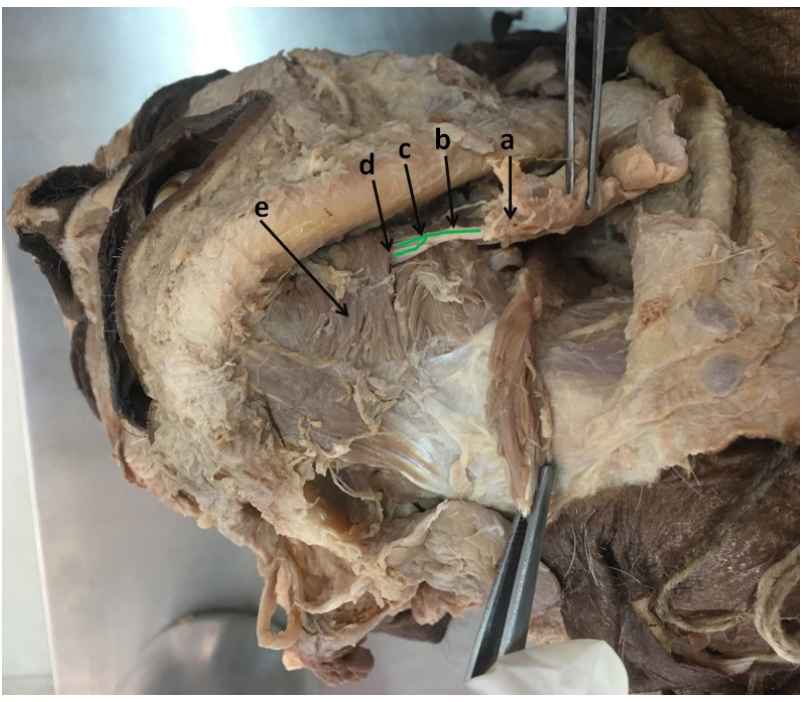

Fig. 1A: Photograph showing unusual path of the accessory submandibular duct (a) superficial part of the submandibular salivary gland (b) accessory submandibular duct (c) bifurcation of accessory submandibular duct (d) mylohyoid muscle pierced by bifurcated accessory submandibular duct (e) mylohyoid muscle.

These two bifurcated branches of accessory duct passed in the space between the hyoglossus muscle medially and the mylohyoid muscle laterally and had separate openings in to the oral cavity. One branch of the bifurcated accessory duct opened through a papilla 
in the floor of the mouth behind the lower incisor tooth. Second branch of the bifurcated accessory duct joined the main duct (Wharton's duct) to open in left sublingual papilla on the left side of the lingual frenulum (Fig. 1B). The main duct (Wharton's duct) of this side (left side) was emerging from deep part of the gland and had normal path. Near its terminal part it was joined by the second branch of the accessory duct and opened at the same side (left side) of the sublingual papilla (Fig. 1B). The right submandibular duct of this cadaver appeared normal with suitable ending in the floor of the mouth.

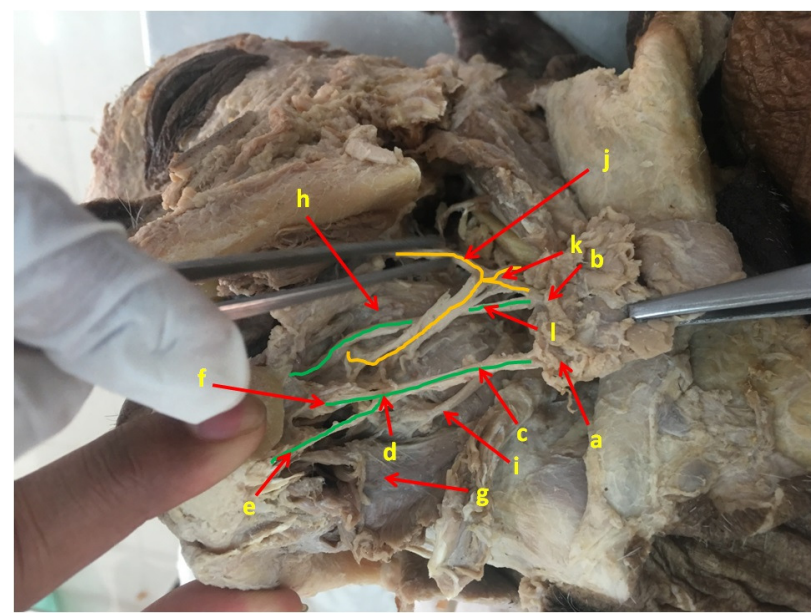

Fig. 1B: Photograph showing deep structures of photograph "A" after horizontal incision on mylohyoid muscle to reflect superolaterally and inferomedially. (a) superficial part of the submandibular gland (b) deep part of the submandibular gland (c) accessory submandibular duct from superficial part of gland (d) bifurcation of accessory submandibular duct (e) one branch of the bifurcated accessory duct opened through a papilla in the floor of the mouth behind the lower incisor tooth (f) second branch of the bifurcated accessory duct joined the main duct to open in left sublingual papilla (g) reflected part of mylohyoid muscle (h) hyoglossus muscle (i) hypoglossal nerve (j) lingual nerve (k) submandibular ganglion (I) main submandibular duct (Wharton's duct) from deep part of the gland.

In two cadavers, submandibular regions of right side had duplication of duct i.e. two submandibular ducts in a salivary gland. Location and opening of accessory duct was that in these two cases, anatomical variation was in the form of duplication of ducts, that one duct was main duct and second duct was accessory duct (Fig. 2). Both ducts emerged separately from the deep part of the gland. The two ducts were parallel in position and present in between the hyoglossus and mylohyoid muscle. The main duct was larger and inferior in position and accessory duct was slightly narrower and superior in position. Initially, ducts were between the lingual and hypoglossal nerve on hyoglossus muscle. The lingual nerve was above the duct, then it passed between two ducts and crossed lateral side of the inferior duct and finally ascends medially winding round the lower border of the duct (Fig. 2). The terminal part of ducts had independent opening into the floor of mouth in sublingual papilla on left side of frenulum of the tongue.

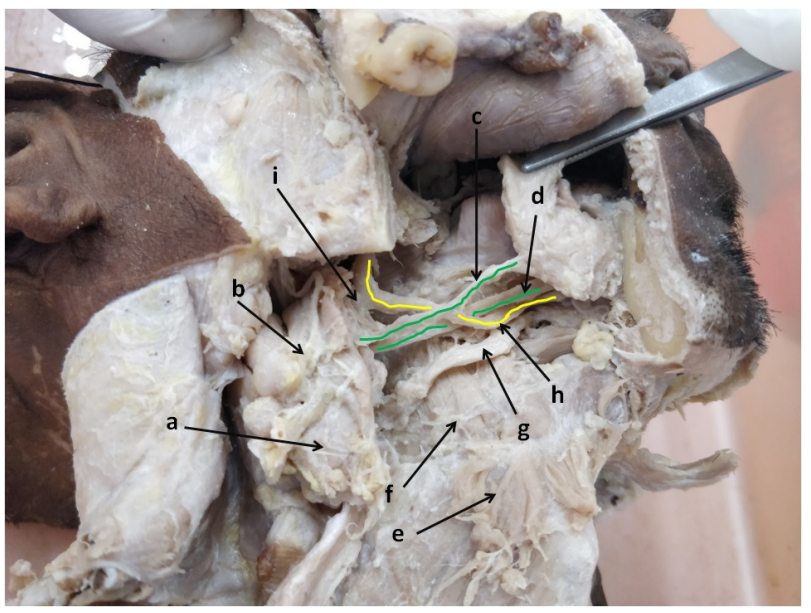

Fig. 2: Photograph showing a submandibular region of right side, having two submandibular ducts (a) superficial part of the submandibular gland (b) deep part of the submandibular gland (c) accessory submandibular duct from deep part of gland (d) main submandibular duct (Wharton's duct) from deep part of the gland (e) reflected part of mylohyoid muscle (f) hyoglossus muscle (g) hypoglossal nerve (h) lingual nerve (i) submandibular ganglion.

\section{DISCUSSION}

The submandibular gland develops bilaterally during the $6^{\text {th }}$ week of fetal life as an endodermal outgrowth from the floor of the alveologingival groove [12]. The edge of the floor of the alveologingival groove gradually fuse together to form the submandibular duct, if the duct branches early or invaginates in two places it may lead in rare case for the formation of an accessory submandibular gland and duct [8-10]. Accessory submandibular ducts are usually smaller and run parallel to the main duct [10].

Waller (1934) described an embryo in which the submandibular duct opened into the pharynx near the isthmus of the fauces [13]. Rose (1932) described a case in which Wharton's duct bifurcate, with one end opening into the sublingual papilla and second end opening into the mouth opposite the second molar tooth [14]. Manzur-Villalobos et al. (2016) reported a cadaver in which an externally located right 
submandibular duct anastomosed with the parotid duct and opened into the buccal mucosa adjacent to the second molar [15]. Humberto Ferreira-Arquez (2017) observed the excretory duct of the left submandibular gland had an external location that ascends and crosses vertically off the body of mandible, in its termination, it is divided in four ducts that had separate openings into the oral cavity upon a small papilla independently, opposite to the first and second lower molar crown [16].

In present study, an accessory duct of left submandibular gland had an external location (Fig. 1A.). The accessory duct was emerging from superficial part of the gland, then crossed the superficial surface of mylohyoid muscle and bifurcated. Then the ducts pierced mylohyoid muscle and passed deep to mylohyoid muscle (Fig. 1A). One branch of bifurcated duct was opening into a papilla in the floor of mouth behind the lower incisor tooth. Second branch of bifurcated duct anastomosed with the terminal part of main duct of same (left) side and then opened into sublingual papilla with the main duct (Fig. 1B). The main duct of this side had normal path and opened in sublingual papilla (Fig. 1B).

Using digital sialography and magnetic resonance imaging Gadodia et al. (2007) identified a unilateral submandibular duct duplication with a small duct of 2 $\mathrm{cm}$ in length passing close to the main submandibular duct and draining a small accessory gland [10].

Previous studies have also reported double duct of the submandibular gland [17-20]. The presence of double duct is important for treating bilateral dry eyes with a technique has been described in which severe keratoconjunctivitis sicca is managed by microvascular autologous submandibular gland transfer. In this operation, the Wharton's duct is transferred with the submandibular gland to the upper lateral conjunctival fornix to replace the lacrimal gland. One of the key elements of the operation is harvesting of an intact duct [20].

In our study, duplication of submandibular duct was found in two submandibular glands, both ducts emerged separately from the deep part of submandibular gland and ended independently into sublingual papilla (Fig. 2).

The presence of radiolucent stones or disease in accessory duct may be overlooked so, information regarding the possibility of additional ducts is essential for oral surgeons and radiologists. Therefore, it is important to know the different anatomical variation that can be present in the excretory duct of salivary glands, because these variations can confuse the real diagnosis for surgeons and to avoid any complication or laceration of the duct [21]. It is essential for radiologist to facilitate and assist in the diagnosis of these ducts by radiographic studies $[18,22]$. These structural changes are called anatomical variations which may be present with no functional impairment in the individual. It is very important to report these finding so further studies can be initiated for such variation or anomaly.

\section{CONCLUSION}

The anatomical course of main submandibular duct or Wharton's duct are known but few conclusive reports on accessory submandibular duct and its unusual path are there. We found cases where accessory submandibular duct were present i.e. duplication of submandibular duct in two cases and unusual path of accessory submandibular duct in one case. Our study showed that the presence of accessory submandibular ducts are frequent. The morphological feature of the submandibular duct reported in the present case is divergent from those of the earlier reported cases.

These anatomical variations may be the cause of complications or reasons for injury during surgery. This study was done on the presence of accessory submandibular duct and its unusual path. It will provide a useful reference for clinical applications and surgical procedure in the floor of the mouth. A thorough anatomical knowledge of these variations is very useful for anatomists, ophthalmologists, oral and maxillofacial surgeons, plastic surgeons, otolaryngologists and radiologists.

\section{Conflict of interest: None}

Funding: None

\section{REFERENCES}

1. Standring S. Oral cavity. Gray's Anatomy- The Anatomical Basis of clinical practice. Spain, Elsevier Limited, $41^{\text {st }}$ ed., 2016; 527-531.

2. Datta AK. Submandibular and Parotid Region, Essential of Human Anatomy- Head \&Neck. Kolkata, Current Books International, $5^{\text {th }}$ ed., 2009; 140-142.

3. Norman S. Williams. Disorder of the salivary glands. Bailey \& Love's short practice of surgery. London, New York, CRC Press Taylor \& Francis Group, 26 ${ }^{\text {th }}$ ed., 2013; 726. 
4. Josef E. Fischer. Surgery of the submandibular and sublingual salivary glands, Fischer's Mastery of Surgery, vol. 1, Gurgaon, Wolters Kluwer India Pvt Ltd. $6^{\text {th }}$ ed., 2012; 298-300.

5. Gary C. Schoenwolf. Developmant of the salivary gland. Larsen's Human Embryology, China, Elsevier Churchil Livingstone, $5^{\text {th }}$ ed., 2015; 468.

6. Gates GA, Johns ME. Diagnostic radiology. In: Paparella MM, Shumrick DA, editors. Otolaryngology. $2^{\text {nd }}$ ed., Philadelphia, Pennsylvania, USA: Saunders.1980; pp.1067-86.

7. Rice DH. Diagnostic imaging. In: Cummings $\mathrm{CW}$, Fredrickson JM, Harker LA, Krause CJ, Schuller DE, editors. Otolaryngology; Head and Neck. $1^{\text {st }}$ ed. St Louis, Missouri, USA: Mosby. 1986; pp. 987-98.

8. Kuroyangi N, Kinoshita H, Machida J, Suzuki S, Yamada Y. Accessory duct in the submanibular gland. $J$ Oral Maxillofac Surg Med Pathol. 2007; 19:110-12.

9. Codjambopoulo P, Ender-Griepekoven I, Broy H. Bilateral duplication of the submandibular gland and the submandibular duct. Rofo. 1992; 157:185-6.

10. Gadodia A, Seith A, Neyaz Z, Sharma R, Thakkar A. Magnetic resonance identification of an accessory submandibular duct and gland: An unusual variant. J Laryngol Otol. 2007; 121:e18.

11. Rachel Kosi. Anterior triangle of the neck. Cunningham's Manual of Practical Anatomy, vol. 3, Head,Neck and Brain. United Kingdom, Oxford university Press, $16^{\text {th }}$ ed., ,2018; 51-56.

12. Pownell PH, Brown OE, Pransky SM, Manning SC. Congenital abnormalities of the submandibular duct. Int $\mathrm{J}$ Pediatr Otorrhonolaryngol. 1992; 24:161-9.

13. Waller WH. Ectopic submaxillary ostium near the isthmus of the fauces. Anat Rec.1934; 58: 111-7.
14. Rose BH. Bifurcation of the submaxillary duct. Am J Surg.1932; 17:257-8.

15. Manzur-Villalobos I Perez-Bulla L, Fang L. Anatomical variation of submandibular gland duct. Scholars J Dent Sci. 2016; 3(1):12-4.

16. Humberto Ferreira-Arquez. Anatomical variation of the submandibular gland duct. A unreported anomaly. International Archives of Medicine. Section: Human Anatomy. 2017; 10 (268).

17. Chen SR, Li WB, Zhu W. The double duct of the submandibular gland --- 1 Case. Chin J Clin Anat. 2000; 18:88.

18. Gadodia A, Seith A, Neyaz Z, Sharma R, Thakkar A. Magnetic resonance identification of an accessory submandibular duct and gland: an unusual variant. The Journal of laryngology and otology. 2007;121(9):e18.

19. Towers JF. Duplication of the submandibular salivary duct. Oral Surg Oral Med Oral Pathol. 1977; 44:326.

20. Zhang L, Xu H, Cai Z, Mao C, Wang Y, Peng X, Zhu Z, Yu G. Clinical and anatomical study on the duct of the submandibular and sublingual gland. J Oral Maxillofac Surg. 2010; 68(3):60610.

21. Stork K, Hope A, Gunzel T, Jungehulsing M; Removal of Wharton's duct during submandibular gland excision. The Laryngoscope. 2008;118(5):810-2.

22. Harrison DJ. Magnetic resonance identification of an accessory submandibular duct and gland: an unusual variant. The Journal of Laryngology and otology. 2008; 122(9):1015. 